\title{
Seasonal Dynamics of Taphrina deformans Inoculum in Peach Orchards
}

\author{
V. Rossi, M. Bolognesi, and S. Giosuè
}

Institute of Entomology and Plant Pathology, "S. Cuore" Catholic University, Via E. Parmense 84, 29100 Piacenza, Italy. Accepted for publication 6 September 2006.

\begin{abstract}
Rossi, V., Bolognesi, M., and Giosuè, S. 2007. Seasonal dynamics of Taphrina deformans inoculum in peach orchards. Phytopathology 97:352358.

The dynamics of the inoculum of Taphrina deformans were studied during a 4-year period by (i) inspecting curled leaves for the presence of asci, (ii) placing deposition spore samplers within the tree canopies, and (iii) exposing potted peach plants (trap plants). These three approaches produced consistent results. Four main periods characterized the dynamics of the inoculum: the first period coincides with the parasitic stage

ascospores in $96 \%$ of the samplings. Rainfall was not necessary for ascospore dispersal, which was favored by air temperature $<20^{\circ} \mathrm{C}$ and relative humidity $\geq 80 \%$ or wetness duration $>8 \mathrm{~h}$. In summer and autumn (second period), blastospores were trapped in 54 and $24 \%$ of samplings, respectively, with low spore numbers. In the winter (third period), blastospores were trapped in the lowest numbers and in only $6 \%$ of samplings. In late winter to early spring (fourth period), blastospores were found in $56 \%$ of samples, with increasing numbers. Rainfall significantly influenced blastospore dispersal and temperature was correlated with the seasonality found during the saprophytic stage.
\end{abstract} of the pathogen's life cycle and the other periods with the saprophytic stage. Mid- to late spring (first period) was characterized by the presence of asci on infected leaves which produced and ejected large quantities of
Additional keywords: latent and infectious periods, Prunus persica.
Taphrina deformans (Berk.) Tul. is the causal agent of leaf curl, a disease commonly occurring wherever peach (Prunus persica L.) is grown. Under favorable conditions, it can cause severe early defoliation and crop loss on all peach and nectarine cultivars (24).

This ascomyceteous fungus is dimorphic, with a parasitic mycelial stage on plant hosts and a saprophytic yeastlike stage (1). Both blastospores and ascospores initiate the mycelial stage on the surface of the young host tissue: mycelia grow penetrating into the tissues of the host and spread between the cells (22), stimulating excessive cell growth and enlargement and producing an uneven expansion of the leaf. Hyphal strands aggregate in the subcuticular region, and some of the hyphal cells enlarge to form ascogenous cells. These cells enlarge and elongate, exert pressure on the host cuticle from below, and break through to form a compact surface layer of naked asci on the plant epidermis $(3,23)$. Each ascus usually produces eight one-celled, oval ascospores, which are released into the air as the mature asci rupture. Soon after they are formed, the ascospores produce small, round or ovoid blastospores by budding. This process may begin before the ascospores are released from the asci and continue after the ascospores have been released. The resulting fungal colonies persist throughout the winter and provide the source of infection in the following spring.

The fate of the fungus from the time the ascospores are discharged until the establishment of infection in the following year has been much discussed. It has been found that spores of $T$. deformans lodge on the surface of trees during the summer, fall, and winter, large numbers of viable spores being found in all the plant material collected from affected trees $(7,9,11)$, especially in bud scales (21). The presence of $T$. deformans inoculum on dormant buds also has been demonstrated by obtaining successful

Corresponding author: V. Rossi; E-mail address: vittorio.rossi@unicatt.it

DOI: 10.1094/PHYTO-97-3-0352

(C) 2007 The American Phytopathological Society infections on potted peach plants by wetting plants at bud break that had been exposed to natural inoculum in a severely affected orchard the previous year (25). Ascospores are discharged forcibly in late spring to early summer and deposited in the canopy of the affected trees (28). At this time, however, many shoots are less than one-half the length they will attain by the end of the growing season, and they do not have buds with scales, but only bud fundaments covered by the base of the petiole. Therefore, the presence of blastospores on bud scales along the entire shoot needs further investigation.

Fitzpatrick (11), noting that spores budded readily in very dilute nutrient solutions, argued that a certain amount of growth is possible upon the surface of trees whenever they are wet with rain for any extended period, so that the fungus becomes part of the normal surface mycoflora of peach trees. Also, investigations by Caporali (6) and Rossi and Languasco (26) supported this hypothesis. Caporali (8) also suggested that autumn rainfall likely favors spore dispersal within the tree. Darmini (10) demonstrated that inoculum spreads on trees within the orchard between late October and early April, when it causes infection.

Lorenz (18) did not observe appreciable fungal growth in washings from peach leaves, whereas the fungus was able to bud during the entire vegetative period on the shoot tips. Therefore, he (18) stated that only ascospores lodging on shoot tips continue to bud, so that they cover shoot tips and keep pace with growth of the host all season. The ability of spores to survive adverse conditions $(18,20,22)$ should enable them to remain viable on the shoot axis until the formation of buds. Furthermore, Lorenz (18) did not consider rainfall to be important in dispersing spores within the tree because the disease regularly affects shoots in the top and in the external parts of the canopies that are unlikely to be hit by rain-dispersed inoculum. Experiments of Mix (22) seem to support Lorenz's hypothesis because shoots that were covered with transparent bags during the period of ascospore dispersal were disease free the following spring. 
These two hypotheses have different epidemiological meanings. In the first, the fungus is active on the trees over the season and the inoculum redistributes by rain splash. In the second, the pathogen spreads only during the period of ascospore production and afterward it remains quiescent on the plant surfaces, except for the tips of the growing shoots. Apart from the abovementioned studies, there is no additional evidence to support either Fitzpatrick's (11) or Lorenz's (18) hypotheses. The behavior of T. deformans inoculum between ascospore discharge and infection in the following year has not actually been ascertained.

The objectives of this study were to (i) determine the dynamics of $T$. deformans inoculum over the season and (ii) relate ascospore and blastospores trap catches to stages of the disease cycle (parasitic or saprophytic) of the pathogen, time of the season, and environmental conditions.

\section{MATERIALS AND METHODS}

Production of asci and infectious period. Between 1999 and 2002, observations were made in a peach orchard of cv. Julia, located in Zattaglia (Ravenna, North Italy), a peach-growing area in the hills of the southern Po Valley ( $\approx 300 \mathrm{~m}$ above sea level). Trees were 13 years old in 1999. They were palmate-trained, spaced $4.6 \mathrm{~m}$ between rows and $3 \mathrm{~m}$ between plants, cropped following commercial practices, but not sprayed with fungicides. Hourly air temperature $(\mathrm{T})$, relative humidity $(\mathrm{RH})$, rain $(\mathrm{R})$, and wetness duration (W) were recorded by a thermo-wetness-hygrograph and a rainfall recorder (model UM 7200/E and UM 8100, respectively; SIAP, Bologna, Italy) placed inside the orchard.

In all, $\approx 150$ to 600 shoots were selected arbitrarily and tagged within the canopy of 10 trees each year, and were inspected two to five times per week starting from bud break. On each inspection, data on disease progress were collected in such a way as to characterize and separate each infection event (25). The period when each infection occurred was inferred by going back from the date of symptom appearance to the beginning of incubation period, the latter calculated as a function of air temperature (25). For instance, first disease symptoms in 2002 appeared on 9 March, average air temperature of the previous days was $10.4^{\circ} \mathrm{C}$, and the estimated incubation period was $24 \pm 1.4$ days. Therefore, it was inferred that the infection occurred on 15 February, when there was a $14-\mathrm{mm}$ rainfall, with a wet period of $28 \mathrm{~h}$ at $6.9^{\circ} \mathrm{C}$.

The presence of asci on the upper surface of infected leaves was recorded with the aid of a handheld magnifying lens $(\times 7)$. Therefore, it was possible to determine the time elapsed between infection and onset of first visible asci (i.e., the latent period) and the duration of ascus production on leaves (i.e., the infectious period) for each infection event. These periods were expressed as both number of days and degree days (DD). To calculate DD, the daily average temperature was accumulated over the period considered, with base $0^{\circ} \mathrm{C}$.

Dynamic of $T$. deformans inoculum during the season. To quantify inoculum of the pathogen, two different methods were used, spore samplers (28) and trap plants (10).

Deposition spore samplers were constructed by using microscope slides ( 26 by $76 \mathrm{~mm}$ ) covered with a double-layer adhesive tape (12 mm wide, model Tesa; Beiesdford SpA, Milano, Italy), so that the trapping surface was $912 \mathrm{~mm}^{2}$. Twelve samplers were placed randomly within the canopy of four trees infected by leaf curl and fixed to the branches by cloth clips, with the adhesive surface facing upward. New samplers were placed in the orchard every 3 to 4 days and each sampler remained there for a 24-h period (from 10:00 a.m.); 223 samplings were considered in aggregate between 15 May 1999 and 1 July 2001. To enumerate T. deformans spores, the adhesive tapes were examined microscopically $(\times 250)$. Four equidistant transects across the long axis of the tape were scanned at 25 regular intervals, so that 100 fields of vision per tape were examined. Spore numbers were corrected for the proportion of the tape examined and expressed as spores caught per square centimeter over a 24-h exposure.

Identification of spores as either ascospores or blastospores was made considering spore morphology and size $(12,13,19,20,23)$ and the presence of spore groups embedded in a matrix as described by Yarwood (28). To limit confusion with other microorganisms, morphological features (shape, size, bud formation, and optical aspect of the cytoplasm) of the most important yeasts and yeast-like fungi associated with peach surfaces (4) were collected in a diagram $(2,16)$ and compared with those of $T$. deformans. Before starting spore counting on tapes, the observer was trained to distinguish these features with the aid of photomicrographs. In cases of uncertainty, spores were not counted as T. deformans. However, some misidentifications cannot be totally excluded.

Two-year-old potted peach plants, cv. Early Maycrest, were used as trap plants. These plants were grown far from any $T$. deformans inoculum source under a cover and then exposed in the orchard of Zattaglia, below the canopy of trees showing severe leaf curl symptoms, to receive a natural inoculum. In the first experiment, trap plants were exposed in two periods: 14 February to 1 June 2001 (3 plants) and 14 April to 31 May 2002 (10 plants). During these periods, plants were exposed to the inoculum present in the orchard air and to ambient weather conditions. Plants were observed carefully at 2-day intervals as previously described to determine each infection event. In a second experiment, six groups of eight plants were exposed in turn in the orchard for $\approx 2$ months between 24 April 2001 and 21 February 2002. At the end of each exposure period, plants were removed and placed under a cover until bud break. At bud break (shoot tip $2 \mathrm{~mm}$ in length), all the plants were placed in a mist chamber $(100 \% \mathrm{RH})$ at $10^{\circ} \mathrm{C}$ and kept wet for $48 \mathrm{~h}$, taking care that water did not drip from plant parts. At the end of the wetting period, plants were placed in growth chambers at $15^{\circ} \mathrm{C}$. Under the abovementioned conditions, the inoculum of $T$. deformans deposited onto the potted plants during the exposure period should have caused infection (25). Plants then were inspected to determine time of disease onset and incidence of affected shoots.

Data analyses. Records from spore samplers were split into two groups. The first group included the data from samplers exposed during the parasitic stage of the fungus. This period was determined based on both the presence of asci on the curled leaves and the prevalence of ascospores on samplers. Spore counts belonging to this group also included a few blastospores, likely arising from those asci where ascospores budded within the ascus (28). The second group included the spore counts from samplers exposed during the saprophytic stage; they included only blastospores.

Spore counts were used to calculate summary statistics and frequencies of spore trap samples with spores over total samples collected in different time periods (for instance in the different seasons) or under particular environmental conditions (for instance, samplers exposed during rainfall). Statistical differences between spore trap catches in different time periods or environmental conditions were tested by the $t$ test for means and by the Kolmogorov-Smirnov test for frequencies, under the null hypothesis of equality of the data sets to be compared. Relationships between spore trap catches and meteorological conditions also were investigated by calculating Pearson's coefficients of correlation. All the statistical analyses were performed using SPSS (version 11.5; SPSS Inc., Chicago).

\section{RESULTS}

Onset and length of the ascal stage. Twenty-three infection events were observed during the 4 years of the study (Table 1). 
The maximum number of events per year was nine, between 9 February and 4 May 2001. The earliest disease symptoms appeared on 12 March 2001 and the latest on 20 May 2002, after an average incubation period of $21.4 \pm 4.4$ days.

The first asci appeared 51 days after infection, on average, with high variability between infection events (Table 1). Minimum latent period was 36 days (last infection of 2001), maximum 69 days (first infection of 1999); the standard deviation (s.d.) was 9.3 days, with a coefficient of variance (CV) of $18.2 \%$. The corresponding DD showed less variability; it averaged 715 DD, with s.d. of $75 \mathrm{DD}$ and a CV of $10.5 \%$.

The infectious period ranged from 9 to 15 days (Table 1) with an average of 12.1 days (s.d. of 2.02) and 220.7 DD (s.d. of 44.93); the CV was 16.7 and $20.4 \%$, respectively. Because of repeated infection events during the season, asci were found on infected leaves between 13 May and 13 June 1999 (205 DD), between 30 April and 20 June 2000 (185 DD), between 7 April and 19 June 2001 (270 DD), and between 21 April and 14 June 2002 (218 DD). Therefore, the total infectious period ranged between 31 days in 1999 and 73 days in 2001. However, the DD were quite consistent over the years, the maximum difference between years being $86 \mathrm{DD}$.

Based on the latter result, the probability distribution over time for the presence of asci on infected leaves was determined; time is calculated as DD after the first appearance of disease symptoms. The distribution did not significantly differ from a normal distribution ( $\mathrm{Z}$ of Kolmogorov-Smirnov $=1.26, n=530$, $P=0.085$ ), with an average 574.1 DD and s.d. 82.83 DD (Fig. 1).

Ascospore dispersal during the parasitic stage. During the infectious periods of 1999 to 2001, spore samplers were exposed for 45 24-h periods within the canopies of affected trees. During this period, both ascospores and blastospores were present at the same time; however, many fewer blastospores were trapped compared with ascospores.
Ascospores were caught in 43 exposure periods (96\%), with 0.1 to 79 ascospores $/ \mathrm{cm}^{2}$ of trapping surface (Fig. 2). In 1999, $\approx 70 \%$ of shoots were affected by leaf curl; 52 ascospores $/ \mathrm{cm}^{2}$ were trapped in aggregate over eight samples, with a peak of 28 asco-

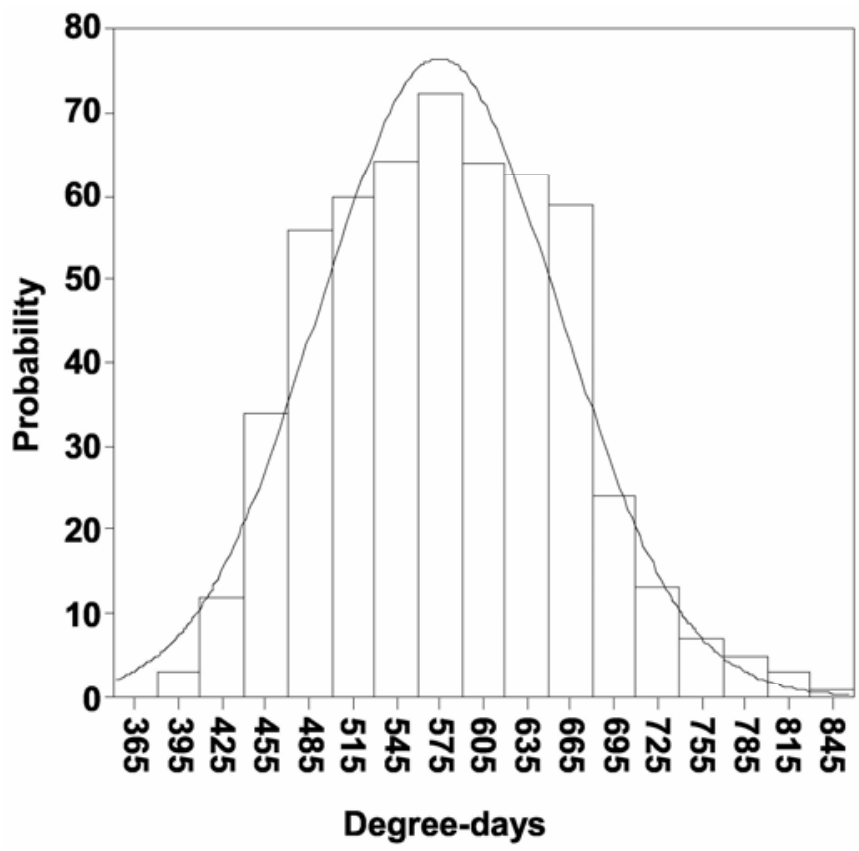

Fig. 1. Probability distribution for the presence of Taphrina deformans asci on peach leaves infected by leaf curl over time (expressed in degree-days, base $0^{\circ} \mathrm{C}$ ) after the appearance of disease symptoms, in a peach orchard located at Zattaglia (northern Italy), 1999 to 2001. Line shows the fit of the normal distribution to data (average 574.1; standard deviation 82.83).

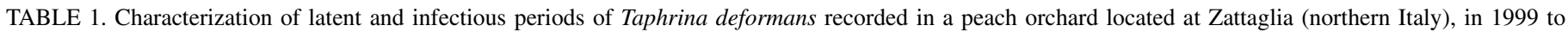
2002

\begin{tabular}{|c|c|c|c|c|c|c|}
\hline \multirow[b]{2}{*}{ Infection $^{\mathrm{a}}$} & \multirow[b]{2}{*}{ Disease onset } & \multirow[b]{2}{*}{ Presence of asci } & \multicolumn{2}{|c|}{ Latent period } & \multicolumn{2}{|c|}{ Infectious period } \\
\hline & & & Days & $\mathrm{DD}^{\mathrm{b}}$ & Days & $\mathrm{DD}^{\mathrm{b}}$ \\
\hline \multicolumn{7}{|l|}{ Year 1999} \\
\hline 5 March & 2 April & 13-26 May & 69 & 826.5 & 13 & 145.4 \\
\hline $26 \mathrm{March}$ & 15 March & 20-31 May & 55 & 770.7 & 11 & 231.4 \\
\hline 8 April & 29 April & 28 May-7 June & 50 & 789.9 & 10 & 208.1 \\
\hline 18 April & 5 May & 31 May-13 June & 43 & 750.4 & 13 & 288.4 \\
\hline \multicolumn{7}{|l|}{ Year 2000} \\
\hline $1 \mathrm{March}$ & 25 March & 30 April-13 May & 60 & 745.4 & 13 & 260.0 \\
\hline $28 \mathrm{March}$ & 15 April & 13-27 May & 46 & 718.0 & 14 & 285.9 \\
\hline 3 April & 20 April & 13-24 May & 40 & 650.1 & 11 & 220.3 \\
\hline 9 April & 26 April & 18-31 May & 39 & 690.3 & 13 & 259.9 \\
\hline 29 April & 20 May & 10-20 June & 42 & 865.7 & 10 & 224.8 \\
\hline \multicolumn{7}{|l|}{ Year 2001} \\
\hline 9 February & 12 March & 7-17 April & 57 & 661.4 & 10 & 112.4 \\
\hline 24 February & 19 March & 17 April-1 May & 52 & 620.5 & 14 & 141.4 \\
\hline 2 March & 27 March & 1-15 May & 60 & 737.7 & 14 & 260.9 \\
\hline 9 March & $31 \mathrm{March}$ & 6-20 May & 58 & 757.3 & 14 & 260.4 \\
\hline 27 March & 18 April & 20-29 May & 54 & 744.7 & 9 & 186.3 \\
\hline 7 April & 30 April & 24 May-2 June & 47 & 669.1 & 9 & 207.6 \\
\hline 11 April & 13 May & 4-14 June & 54 & 859.0 & 10 & 204.6 \\
\hline 16 April & 5 May & 28 May-8 June & 42 & 650.9 & 11 & 230.3 \\
\hline 4 May & 19 May & 9-19 June & 36 & 702.7 & 10 & 215.9 \\
\hline \multicolumn{7}{|l|}{ Year 2002} \\
\hline 15 February & 9 March & 21 April-6 May & 65 & 617.3 & 15 & 217.9 \\
\hline 21 February & 13 March & 24 April-9 May & 62 & 620.2 & 15 & 219.2 \\
\hline 5 March & 23 March & 2-15 May & 58 & 629.9 & 13 & 199.7 \\
\hline 8 April & 25 April & 18 May-2 June & 40 & 644.5 & 15 & 276.8 \\
\hline 20 April & 11 May & 3-14 June & 44 & 722.5 & 11 & 219.3 \\
\hline
\end{tabular}

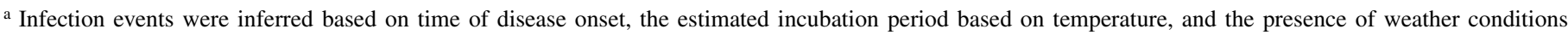
making infection possible (25).

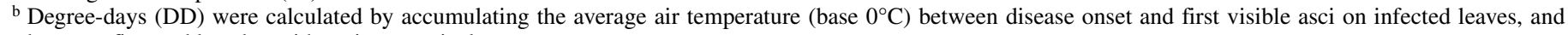
between first and last day with asci, respectively. 
spores $/ \mathrm{cm}^{2}$ on 18 May (Fig. 2A). In 2000, 96\% of shoots showed disease symptoms; total ascospores caught were $141 / \mathrm{cm}^{2}$ over 14 samples, with peaks on 7 and 10 May $\left(36\right.$ and $79 / \mathrm{cm}^{2}$ ascospores, respectively) (Fig. 2B). In 2001, 100\% of the shoots were infected; the trapping season was longer (23 samples) and the total ascospores were $175 / \mathrm{cm}^{2}$. The first peak was observed on 11 April (41 ascospores $\left./ \mathrm{cm}^{2}\right)$ and a second one between 2 and 6 May (total of 75 ascospores $/ \mathrm{cm}^{2}$ ) (Fig. 2C).

The numbers of ascospores caught were significantly correlated with RH $(r=0.581, P=0.00003)$ and $\mathrm{W}(r=0.466, P=0.001)$ (Table 2). Peaks (i.e., $>20$ ascospores $/ \mathrm{cm}^{2}$ per exposure period) consistently coincided with days having $\mathrm{RH}>80 \%$ (Fig. 2) and $\mathrm{W}$ between 8 and $24 \mathrm{~h}$ (data not shown). Few ascospores were caught when the RH was $<80 \%$. The difference between ascospore numbers sampled with $\mathrm{RH} \geq 80 \%$ (8 cases) and with $\mathrm{RH}$ $<80 \%$ (37 cases) was significant (at $P=0.0001$ ), the average of the first group being three times higher.

Rainfall was not necessary for ascospore dispersal. During the two exposure periods in which no ascospores were caught, there

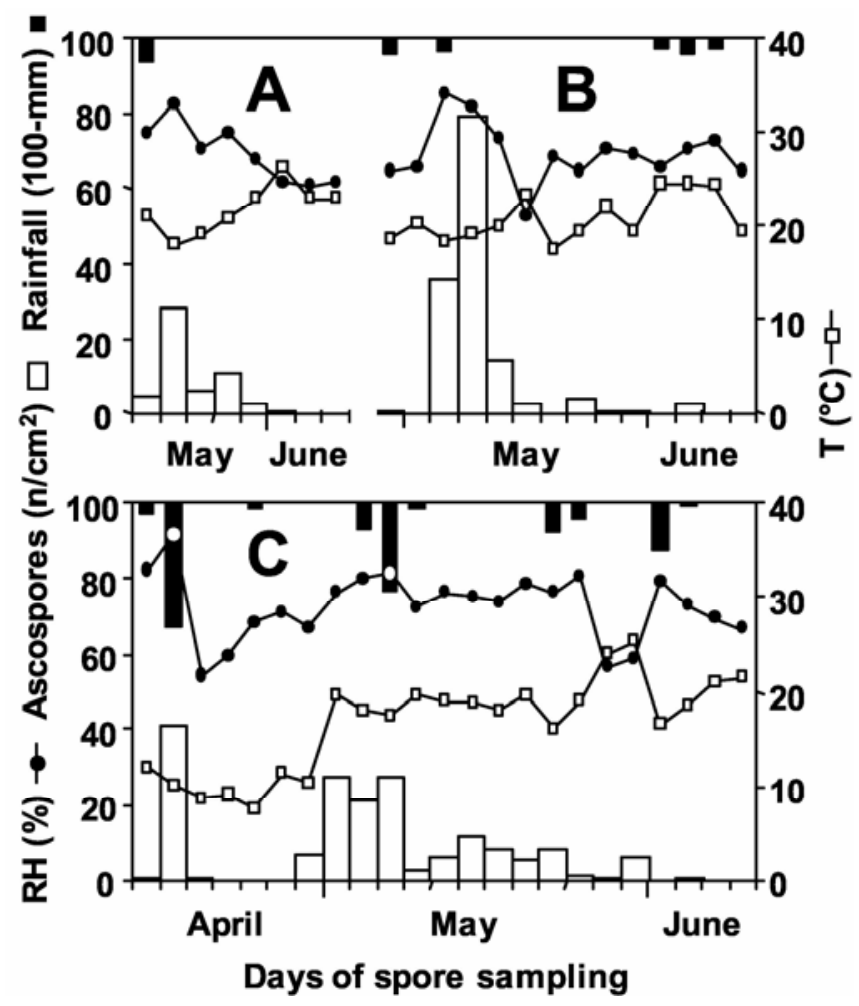

Fig. 2. Numbers of Taphrina deformans ascospores trapped by deposition spore samplers in a peach orchard located at Zattaglia (northern Italy), and corresponding values of air temperature $(\mathrm{T})$, relative humidity $(\mathrm{RH})$, and rainfall. Samplers were exposed within the tree canopies for $24 \mathrm{~h}$ at 2- to 3-day intervals, with the trapping surface facing upward, between A, 15 May and 8 June 1999, B, 30 April and 18 June 2000, and C, 8 April and 14 June 2001 was no rainfall; however, out of the 43 cases in which ascospores were trapped, there was no rain in 27 cases (Fig. 2). There was no significant association between rainfall and exposure periods with or without ascospores trapped $\left(\chi^{2}=1.15, P=0.283\right)$. Nevertheless, there was a significant correlation between rainfall amount and the number of ascospores trapped on the 16 rainy days $(r=$ $0.709, P=0.002$ ) (Table 2).

The correlation between $\mathrm{T}$ and numbers of ascospores trapped was not significant $(P=0.448)$ (Table 2$)$. Nevertheless, ascospore peaks occurred with $\mathrm{T}$ between 10 and $20^{\circ} \mathrm{C}$, whereas few ascospores were caught with $\mathrm{T}>20^{\circ} \mathrm{C}$ (Fig. 2). The difference between ascospores trapped with $\mathrm{T}<20^{\circ} \mathrm{C}$ ( 28 cases) and $\mathrm{T} \geq$ $20^{\circ} \mathrm{C}$ (17 cases) was significant $(P=0.027)$, the average of the first group being nine times higher.

Blastospore dispersal during the saprophytic stage. Two periods in which no asci were present on infected leaves were investigated, mid-June 1999 to the end of April 2000 (Fig. 3A and B) and mid-June 2000 to early April 2001 (Fig. 3C and D). Deposition spore samplers were exposed for 171 24-h periods in total. Blastospores were caught in 53 cases (45.3\%), with 0.1 to 7.6 blastospores $/ \mathrm{cm}^{2}$ of trapping surface (Fig. 3). Numbers of blastospores showed a marked seasonality. In the summer, blastospores were trapped in 54\% of exposure periods, with an average of $1.2 \pm 0.32$ blastospores $/ \mathrm{cm}^{2}$ (maximum 7.6 blastospores $/ \mathrm{cm}^{2}$ ). In the autumn, blastospores were trapped on $24 \%$ of the exposure periods, with $1.0 \pm 0.48$ blastospores $/ \mathrm{cm}^{2}$ (maximum $5.6 / \mathrm{cm}^{2}$ ). In the winter, blastospores were trapped during only $6 \%$ of exposures ( 3 of 51 ), with an average of 0.1 \pm 0.03 blastospores $/ \mathrm{cm}^{2}$ (maximum $0.2 / \mathrm{cm}^{2}$ ). In the spring, blastospores were found in $56 \%$ of samples, with $0.8 \pm 0.39$ blastospores $/ \mathrm{cm}^{2}$ on average (maximum $3.8 / \mathrm{cm}^{2}$ ).

Rainfall was the most important factor influencing catches of blastospores. In 116 exposure periods with no rain, there were only 28 positive catches $(24.4 \%)$ whereas, in the 55 rainy periods, blastospores were trapped during 25 periods (45.5\%). In all, $65 \%$ of the total blastospores trapped were caught during rain events. There was a significant association between exposures during rain periods and blastospore trapping during these periods $\left(\chi^{2}=7.93\right.$, $P=0.005)$. Furthermore, average numbers of blastospores caught during rainy exposures were two times higher than during nonrainy ones $\left(1.5 \pm 0.37\right.$ versus $0.7 \pm 0.21$ blastospores $\left./ \mathrm{cm}^{2}\right)$. The occurrence of rainfall was more important than its amount, because the correlation was not significant $(P=0.98, n=55)$ between the numbers of blastospore and rainfall rates during the rainy exposure periods (Table 2).

The relationship with rainfall did not explain seasonality in the blastospores trapped because distribution of rain during the exposure of spore samplers was almost consistent over the seasons (Fig. 3). On the contrary, T during the exposure periods was significantly correlated with numbers of blastospores $(r=$ $0.49, P=0.00003$ ), and its seasonal variability was consis-tent with that of blastospores trapped: average $\mathrm{T}$ was $7.5^{\circ} \mathrm{C}$ for the exposure periods in winter (range -0.1 to $18.8^{\circ} \mathrm{C}$ ), $14.6^{\circ} \mathrm{C}$ in spring (10.3 to $24.8^{\circ} \mathrm{C}$ ), $23.2^{\circ} \mathrm{C}$ in summer $\left(17.7\right.$ to $29.5^{\circ} \mathrm{C}$ ), and $11.8^{\circ} \mathrm{C}$ in autumn $\left(1.8\right.$ to $\left.23.5^{\circ} \mathrm{C}\right)$. Furthermore, exposure periods with $\mathrm{T}$ between 15 and $25^{\circ} \mathrm{C}$, which was the most favorable temperature

TABLE 2. Correlation coefficients between spore numbers of Taphrina deformans and average temperature (T), average relative humidity (RH), total rainfall (R), and wetness duration (W) measured in concomitance of repeated 24-h exposures of spore samplers during either the parasitic (ascal) or the saprophytic stages of the fungus life cycle ${ }^{\mathrm{a}}$

\begin{tabular}{|c|c|c|c|c|c|c|}
\hline \multirow[b]{2}{*}{ Meteorological parameters } & \multicolumn{3}{|c|}{ Parasitic stage } & \multicolumn{3}{|c|}{ Saprophytic stage } \\
\hline & $r$ & $P$ & $n$ & $r$ & $P$ & $n$ \\
\hline $\mathrm{T}\left({ }^{\circ} \mathrm{C}\right)$ & -0.116 & 0.448 & 45 & 0.316 & $<0.001$ & 171 \\
\hline RH (\%) & 0.581 & $<0.001$ & 45 & -0.117 & 0.126 & 171 \\
\hline W (h) & 0.466 & 0.001 & 45 & 0.146 & 0.057 & 171 \\
\hline
\end{tabular}

a Abbreviations: $r=$ Pearson's coefficient of correlation, $P=$ probability level for $r$, and $n=$ number of spore-trapping periods. 
range for blastospores to bud in environment-controlled experiments (26), were $77 \%$ in summer, 30 to $33 \%$ in spring and autumn, and $6 \%$ in winter.

Leaf curl incidence in plants exposed to inoculum. Infection occurred in the group of plants exposed between 14 February and 1 June 2001 (Table 3). The first asci on the affected trees were observed on 7 April (Table 1); therefore, the two early infections were established before the presence of ascospores in the orchard air and likely were caused by blastospores. Blastospores were caught by spore samplers on 24 February and 4 and 28 March (Fig. 3C). The three infections established in April and May likely were caused by ascospores that were abundant in spore samplers exposed during this period (Fig. 2C). Similarly, in the second group of plants (exposed between 14 April and 31 May 2002), the infection event (20 to 21 April) that preceded the beginning of asci production (21 April to 14 June) (Table 1) affected only $1 \%$

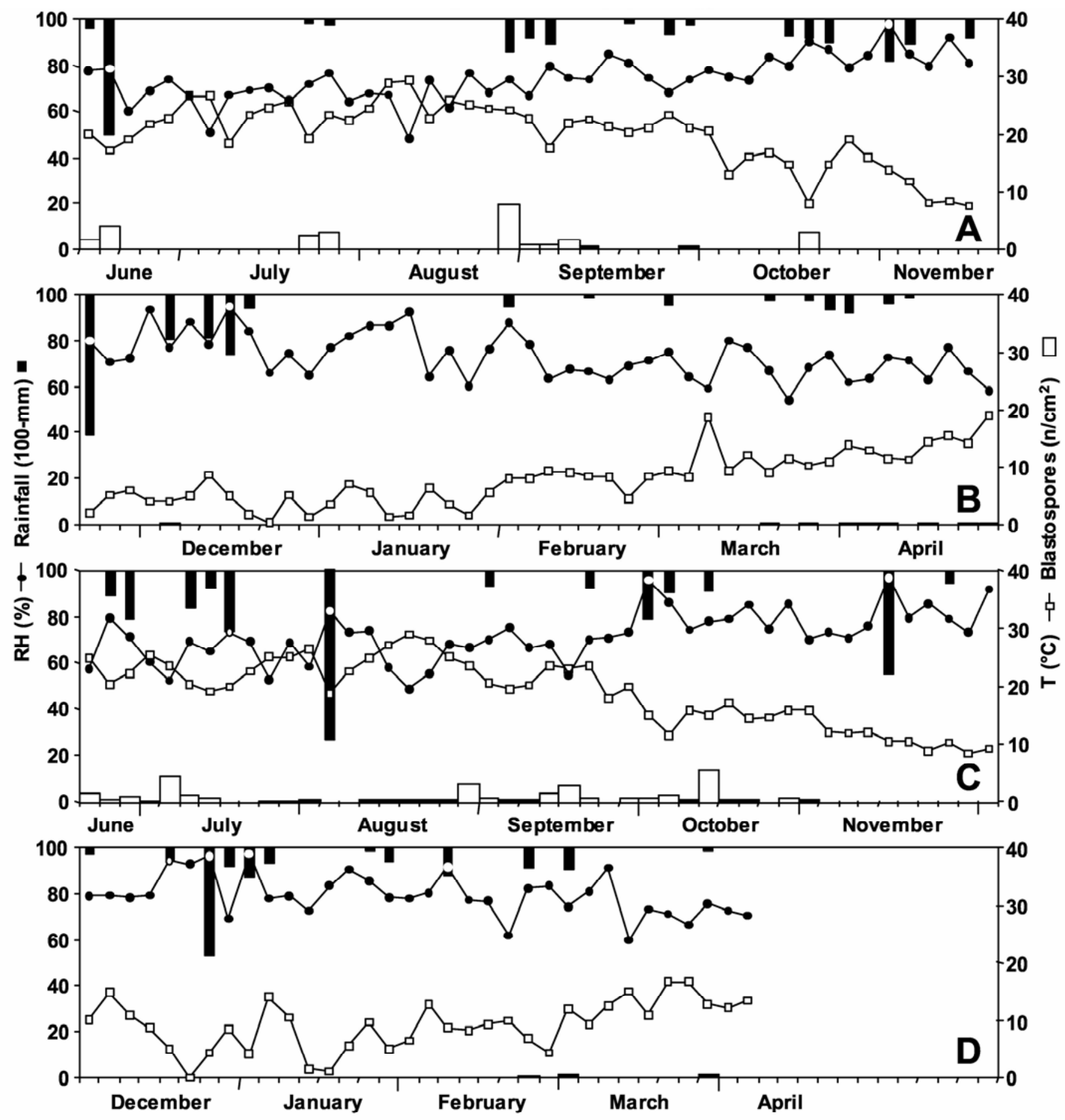

Days of spore trapping

Fig. 3. Numbers of Taphrina deformans blastospores trapped by deposition spore samplers in a peach orchard located at Zattaglia (northern Italy), and corresponding values of air temperature (T), relative humidity (RH), and rainfall. Samplers were exposed within the tree canopies for $24 \mathrm{~h}$ at 2 - to 3-day intervals, with the trapping surface facing upward, between A, 15 June and 17 November 1999, B, 21 November 1999 and 26 April 2000, C, 21 June and 4 December 2000 , and $\mathbf{D}, 8$ December 2000 and 4 April 2001. 
of shoots, while the infection event on 8 to 9 May, that occurred at about the middle of the infectious period, affected $74 \%$ of shoots (Table 3 ).

Plants exposed for 2 months during the infectious period in 2001 (Table 4, group I) received a high inoculum dose, because $48 \%$ of shoots showed leaf curl symptoms the next spring after plants had been maintained under favorable conditions for infection at green tip. Groups II to V, that were exposed during the saprophytic stage of the fungus, showed less severe symptoms, with a maximum $26 \%$ of affected shoots for plants exposed between 24 August and 26 October.

\section{DISCUSSION}

Four main periods characterized the inoculum dynamics of T. deformans in a peach orchard affected by leaf curl. The first (mid- to late spring) coincided with the parasitic stage of the pathogen's life cycle. It was characterized by the presence of asci on infected leaves which produced and ejected large quantities of ascospores in $96 \%$ of the samplings. Rainfall was not necessary for ascospore dispersal, which was favored by air temperature $<20^{\circ} \mathrm{C}$ and high humidity. The other periods corresponded to the saprophytic growth of the fungus. In the second period (summer and autumn), blastospores were trapped in 54 and $24 \%$ of samplings in the summer and in autumn, respectively, with low densities. In the third period (winter), blastospores were trapped in the lowest numbers and in only $6 \%$ of sampling. In the fourth period (late winter to early spring), blastospores were found in $56 \%$ of samples, with increasing numbers. Seasonality in blastospore trappings found during the saprophytic stage was correlated with air temperature, whereas rainfall triggered appreciable blastospore dispersal.

Ascospores were present only during the infectious period of the parasitic stage. Asci began to appear 5 to 10 weeks after infection and 3 to 6 weeks after symptoms were first observed; they continued to be produced for 9 to 15 days thereafter. Because different infection events occurred in succession over the season, the total infectious period ranged from 1 to $>2$ months per season. This was the first quantitative study of the length of the latent and infectious periods. Fitzpatrick (11) stated that the entire cycle from the time of infection to the time of ascospore discharge takes a few weeks. Mix (22) reported that, in 1927, ejection of ascospores began at approximately 2 May and was nearly completed by 20 May.

During the infectious period, ascospores were produced and dispersed in high numbers. There were 6.5 times more ascospores caught on the 45 samplers exposed during the parasitic stage than by the 171 samplers exposed in the saprophytic stage. Consistently, trap plants exposed during the parasitic stage became affected by leaf curl to a greater extent than plants exposed in the saprophytic one. During this period, some blastospores were

TABLE 3. Incidence of shoots affected by Taphrina deformans in potted peach trees exposed to inoculum in a peach orchard showing infection by leaf curl

\begin{tabular}{lcc}
\hline Exposure period, infection events & & \\
\hline 14 February-1 June 2001 & & \\
24 February-9 March & 79 & 23 \\
27-31 March & 79 & 9 \\
7-17 April & 50 & 78 \\
4 May & 50 & 12 \\
20-21 May & 16 & 6 \\
14 April-31 May 2002 & & \\
20-21 April & 269 & 1 \\
8-9 May & 291 & 74 \\
\hline
\end{tabular}

${ }^{a}$ Infection events were inferred based on time of disease onset, the estimated incubation period based on temperature, and the presence of weather conditions making infection possible (25). sampled together with ascospores. Distinction between the two spore types was made based on spore morphology and size. Ascospore groups described by Yarwood (28) were found only occasionally, so that this character was not useful in distinguishing spores. Although some misidentifications may have occurred, it should not have affected the robustness of the results. The origin of the blastospores found during the parasitic stage can be twofold: they can arise from ascospores that had budded within the ascus before ejection or from budding on tree surfaces after ascospores had ejected and been deposited there. The former origin may be more prevalent because (i) budding within asci had been observed frequently in $T$. deformans (28) and (ii) numbers of blastospores found during the saprophytic growth were lower compared with the spores found in the parasitic stage.

Inoculum availability during the parasitic stage was influenced by weather conditions. Air temperature influenced both dynamics of ascus production over time (as DD) and ejection of ascospores from asci. In the orchard, more ascospores were trapped during days with $\mathrm{T}<20^{\circ} \mathrm{C}$ and $\mathrm{RH} \geq 80 \%$ or $\mathrm{W}>8 \mathrm{~h}$ than in warmer and drier conditions. Rossi and Languasco (26) previously showed that, under environment-controlled conditions, $\mathrm{T}<20^{\circ} \mathrm{C}$ favored ascospore production and ejection, with the optimum dispersal occurring at $10^{\circ} \mathrm{C}$. Rainfall was not necessary for ascospore dispersal. Nevertheless, more ascospores were trapped during periods with high RH and presence of wetness or rainfall. Likely, these conditions provide humidity for the production of asci on curled leaves.

Studies of the inoculum dynamics during the saprophytic stage of the fungus produced consistent results that showed that blastospores are spread within the trees during rainfall events over the entire period between the time the ascospores are discharged until the establishment of infection the following spring, and until new ascospores are produced on curled leaves. These results are consistent with earlier studies by Darmini (10) and Mix (22). Darmini (10) exposed potted peach plants for 11 to 61 days in an affected orchard between late October and early April, and then removed them from any further inoculum source. The following spring, 2 to $14 \%$ of shoots on these plants showed leaf curl symptoms. Mix (22) inoculated branches of trees in July to March with cells of $T$. deformans and found that these cells were able to survive and cause infection the following spring on $62 \%$ of shoots; $32 \%$ of shoots were infected in the noninoculated control branches near the inoculated ones, compared with $13 \%$ in remote controls. In another experiment, some shoots were covered by transparent bags for the entire season to prevent any inoculation, whereas other shoots were covered only until early June to prevent inoculation by ascospores. The first group of shoots were disease-free the following spring, whereas 3\% of shoots were affected in the second group compared with $9 \%$ in the uncovered control shoots. In both these experiments, the splashing drops originated by rainfall may have redistributed the inoculum onto the shoots that did not receive direct either artificial or natural inoculation. The effect of rainfall on a large increase in yeast densities on leaves also was demonstrated for apple (15).

The numbers of blastospores found on spore samplers were generally low. It may be explained by the fact that spore samplers were exposed for only 24-h periods and that blastospores likely

TABLE 4. Incidence of shoots infected by Taphrina deformans in five groups of potted peach trees exposed for $\approx 2$ months to inoculum in a peach orchard showing infections by leaf curl

\begin{tabular}{llcc}
\hline Group & Exposure period 2001-02 & Total shoots $(n)$ & Affected shoots $(\%)$ \\
\hline I & 24 April-27 June & 191 & 48 \\
II & 27 June-24 August & 139 & 8 \\
III & 24 August-26 October & 147 & 26 \\
IV & 26 October-17 December & 233 & 7 \\
V & 17 December-21 February & 251 & 10 \\
\hline
\end{tabular}


adhere to tree surfaces (22). Nevertheless, considering that dispersal and deposition go on for the entire season, it can be estimated that blastospores accumulate in great numbers on the tree surfaces (14). Results from potted trap plants used in this work were in agreement with this consideration, because the inoculum they received during the saprophytic stage of the fungus was able to affect up to $>20 \%$ of shoots the following spring.

A marked seasonality in blastospore dispersal was observed. For instance, spore numbers were higher in the summer than in the spring and autumn, and particularly in the winter. The distribution of rain events was quite similar over the seasons; therefore, seasonality was correlated to differences in air temperature that likely affected spore budding: an increased population of blastospores should result in an increased number of them removed by rain splashes. Air temperatures that favored dispersal in the orchard were in agreement with the temperature regimes that favored budding of blastospores under environmentcontrolled conditions (26).

Humidity and nutrient availability also influence the budding of blastospores on peach tree surfaces. A recent study (26) on the effect of these surface-environment factors supported the idea that T. deformans is a part of normal epiphytic mycoflora of peach trees $(11,22)$. Blastospores then can be redistributed on bud scales by rain splash after they have been formed to serve as inoculum for spring infections. Bud scales are the most important niches occupied by $T$. deformans $(4,17,21,27)$ and are likely very hospitable. Bud pubescence can retain spores once they have landed there and maintain high humidity. Because buds develop at the axilla of leaves, they probably receive water gusts from the leaf blades via the flow on the leaf stems. In addition $P$. persica stems, petioles, and stipules, which are in close contact with buds, are rich sources of extrafloral nectaries that excrete fluids containing high sugar concentrations (5) that can increase nutrients on scales.

In conclusion, four main periods characterized the inoculum dynamics of $T$. deformans in peach orchards. The first period lasts from mid- to late spring, when asci on infected leaves produce and eject ascospores; this is the period of maximum inoculum density. Low temperature and high humidity favor ascospore production, whereas rainfall is not necessary for dispersal. During the infectious period, weather con-ditions usually are unfavorable for infection to occur (25); therefore, this inoculum occasionally causes secondary infec-tion cycles (22). The main role of this inoculum is to spread within the orchard, land on plant surfaces, and start epiphytic colonization by budding. The second period occurs in summer until late autumn. The fungus actively colonizes plant surfaces as a saprophyte because temperature is very favorable for budding; humidity and nutrient availability appear not to be limiting factors for growth, especially on scattered sites on the plant (26). Blastospores spread by rain splashes and can immigrate on bud scales where the conditions for growth are likely to be more favorable. The third period lasts from late autumn to late winter, when temperature limits budding activity. The fourth period occurs in late winter to early spring; rising temperature and frequent periods with high humidity allow the fungus to bud and to infect green tips (25), and rain carries the inoculum to young tissues of the shoot tips for infection to occur (25).

\section{ACKNOWLEDGMENTS}

This work is part of research promoted and supported by the EmiliaRomagna Region (Italy) by means of the coordination of the Centro Ricerche Produzioni Vegetali (CRPV).

\section{LITERATURE CITED}

1. Agrios, G. N. 1988. Plant Pathology. Academic Press, Inc., New York.

2. Barnett, J. A., Payne, R. W., and Yarrow, D. 1990. Yeast Characteristics and Identification. 2nd ed. Cambridge University Press, Cambridge.

3. Bassi, M., Conti, G. G., and Barbieri, N. 1984. Cell wall degradation by Taphrina deformans in host leaf cells. Mycopathologia 88:115125.

4. Buck, J. W., Lachance, M.-A., and Traquair, J. A. 1998. Mycoflora of peach bark: Population dynamics and composition. Can. J. Bot. 76:345-354.

5. Caldwell, D. L., and Gerhardt, K. O. 1986. Chemical analysis of peach extrafloral nectary exudate. Phytochemistry 25:411-413.

6. Caporali, L. 1961. Sur l'origine des conidies de Taphrina deformans (Berk.) Tul. vivant a la surface des rameaux de Prunus persica L. C. R. Acad. Sci. Paris 253:890-891.

7. Caporali, L. 1963. Sur le cycle du Taphrina deformans (Berk.) Tul. et le passage de l'état saprophyte à la vie parasitaire. C. R. Acad. Sci. Paris 253:515-518.

8. Caporali, L. 1966. Nouvelles observations sur la biologie et sur le parasitisme du Taphrina deformans (Berk.) Tul. Proc. 1st Congr. Mediterr. Phytopathol. Union 1:36-42.

9. Caporali, L. 1974. Evolution des méthodes de sélection et d'identification des spores fongiques présentes à la surface d'arbres fruitiers. C. R. Acad. Sci. Paris 278:2743-2746.

10. Darmini, M. 1966. Ricerche sulla biologia di Taphrina deformans e sui metodi di lotta contro questo parassita. Riv. Patol. Veg. 4:221-250.

11. Fitzpatrick, R. E. 1934. The life history and parasitism of Taphrina deformans. Sci. Agric. 14:305-326.

12. Ghillini, C. A. 1952. I parassiti vegetali delle piante: Tafrinacee italiane. Ed. Agric. Bologna 7-26.

13. Hanlin, T. R. 1998. Illustrated Genera of Acomycetes, Vol. II. The American Phytopathological Society, St. Paul, MN.

14. Kinkel, L. L. 1997. Microbial population dynamics on leaves. Annu. Rev. Phytopathol. 35:327-347.

15. Kinkel, L. L., Andrews, J. H., and Nordheim, E. V. 1989. Fungal immigration dynamics and community development on apple leaves. Microbiol. Ecol. 18:45-48.

16. Kreger van-Rij, N. J. W. 1984. The Yeasts-A Taxonomic Study. 3rd ed. Elsevier Science Publishers, Amsterdam.

17. Leben, C. 1971. The bud in relation to the epiphytic mycoflora. Pages 117-127 in: Ecology of Leaf Surface Micro-organisms. T. F. Preece and C. H. Dickinson, eds. Academic Press, London.

18. Lorenz, D. H. 1976. Beiträge zur weiteren Kenntnis des Lebenszyklus von Taphrina deformans (Berk.) Tul. unter besonderer Berücksichtigung der Saprostage. Phytopathol. Z. 86:1-15.

19. Martin, E. M. 1925. Cultural and morphological studies of some species of Taphrina. Phytopathology 15:67-76.

20. Martin, E. M. 1940. The morphology and cytology of Taphrina deformans. Am. J. Bot. 27:743-751.

21. Mix, A. J. 1923. Biological and cultural studies of Exoascus deformans. Phytopathology 14:217-233.

22. Mix, A. J. 1935. The life history of Taphrina deformans. Phytopathology 25:41-66.

23. Mix, A. J. 1949. A monograph of the genus Taphrina. Sci. Bull. 33:3167.

24. Pscheidt, J. W. 1995. Leaf curl. Page 22 in: Compendium of Stone Fruit Diseases. J. M. Ogawa, E. I. Zehr, G. W. Bird, D. F. Ritchie, K. Uriu, and J. K. Uyemoto, eds. The American Phytopathological Society, St. Paul, MN.

25. Rossi, V., Bolognesi, M., Languasco, L., and Giosuè, S. 2006. Influence of environmental conditions on infection of peach shoots by Taphrina deforman. Phytopathology 96:155-163.

26. Rossi, V., and Languasco, L. 2007. Influence of environ-mental conditions on spore production and budding in Taphrina deformans, the causal agent of peach leaf curl. Phytopathology 97:359-365.

27. Tavares, S., Inácio, J., Fonseca, Á., and Oliveira, C. 2004. Direct detection of Taphrina deformans on peach using molecular methods. Eur. J. Plant Pathol. 110:973-982.

28. Yarwood, C. E. 1941. The diurnal cycle of ascus maturation of Taphrina deformans. Am. J. Bot. 28:355-357. 